\title{
THE MACROECONOMIC LOSS FUNCTION: A CRITICAL NOTE Thomas Mayer
}

Good people all of every sort

Give heed unto my song

And if you find it wondr's short

It will not keep you long.

\section{Oliver Goldsmith}

The objective function usually employed in evaluating macroeconomic policies is a loss function described in the MIT Dictionary of Modern Economics (Pearce, 1986, p. 255) as a disutility function of policymakers that: "usually contains the squared difference between the actual and desired value of each target variable multiplied by a weight associated with that variable." It cites as an example; $\mathrm{L}=\mathrm{a} 1\left(\mathrm{u}-\mathrm{u}^{*}\right) 2+$ $\mathrm{a} 2\left(\mathrm{p}-\mathrm{p}^{*}\right) 2$, where $\mathrm{L}$ is the loss, the u's are the unemployment rates, the p's the inflation rates, the stars designate the desired rates, and the a's the weights of the two variables. Cecchetti (2000, p. 51) has called this type of loss function (though, written with an output measure in place of unemployment) "the simplest and most commonly used objective function."

The use of such loss functions to evaluate monetary or fiscal policies raises several questions. One is the omission of the higher moments of the variances of output and inflation (see Cecchetti, 2000). A second is its assumption of symmetry, that is the attachment of equal weights to deviations above and below the target. A third is the use of a quadratic function, which is usually justified only 
by its tractability, and sometimes by its innocuousness. (See for instance Waud, 1976, Kunstman, 1984, Horowitz, 1987, Mitchell, 1990). The fourth - the subject of this Note - is the treatment of above-target output and below-target inflation as instances of losses. None of these problems apply to the Taylor rule, since it, while setting a rule for monetary policy, does not try to measure the loss from misses of the inflation and output targets.

\section{Output}

Suppose output exceeds its target, so that the output gap is negative. Why should this be considered a loss? One possibility is that some agents are then required to work involuntary overtime and that shortages develop in some markets. Such losses seem small, because firms can coerce employees to work overtime only to a limited extent, and in most cases only at a substantial cost in overtime pay. A probably much more widely accepted reason for treating output in excess of its target as a lossis that a negative output gap will generate inflation. But the loss from inflation is already included in the loss function. Hence, if the period over which policy is evaluated is long enough for the full inflationary effect of overshooting the output target to show up, then penalizing an overshooting of the output target because it is inflationary, amount to counting the loss from inflation twice; once directly when the inflation rate exceeds its target, and once indirectly 
when the groundwork for this inflation rate is laid.

This does not mean that the inflationary consequence of overshooting the output target should be ignored entirely, because if the overshooting occurs toward the end of the period covered, the resulting loss from the rise in the inflation rate will not be counted. The solution to this problem is to terminate the period over which policy is evaluated at a point when sufficient time has passed for excess demand to have had all its inflationary effect. When evaluating the actual policy followed during a particular period, rather than the effects of a simulated policy this may create a serious problem because by the time the inflationary effect of one episode of excess demand has occurred a new episode of excess demand may have begun. That the loss function should not include a negative output gap does not mean that policymakers are wrong if they adopt a more restrictive policy when output exceeds its target. Given the limited reliability of the inflation forecasts provided by other indicators, information on current or predicted output may provide a useful signal for when a switch to a more restrictive policy is warranted. But an economist fitting a loss function does not need such a signal since he or she, unlike the real-time policymaker, already knows the inflation rate,

Inflation

Whether a moderate shortfall of inflation below its target should be counted as a 
loss depends on why the particular inflation target was chosen. One possibility is that it was chosen because at that time it seemed the lowest inflation rate that was achievable. If so, the loss function should not treat a shortfall of the inflation rate from its target as involving a loss. For example, the Fed's policy in recent years is probably explained much better by assuming that it gave a zero weight to deviations of inflation below its target than by assuming that it gave them the same weight as deviations above the inflation target. Should the loss function used to evaluate monetary policy penalize such a policy?

Or, suppose that policymakers had set the inflation target as high as they did because they believed that, due to nominal wage inflexibility, as shifts in demand occur a lower inflation rate could generate excessive frictional unemployment, or because they believed that with a lower inflation target the zero bound to nominal interest rates would inhibit stabilization policy. Here, too, if the period used to evaluate the policy is long enough, including undershooting of the inflation target in the loss function results in double counting: the undershooting of the inflation rate is counted as a loss when it occurs, and then again when it manifests ${ }^{\mathrm{i}}$ itself in a fall of output. ${ }^{1}$

Another possibility is that the inflation target was set at a certain level to avoid falsifying the public's expectation of inflation. Here treating the shortfall of the 
inflation rate as a loss is appropriate. Even giving it the same weight as an overshooting of the inflation rate seems plausible.

\section{Conclusion}

The standard loss function should not be treated as an off-the-shelf default option that can be added mechanically to an econometric model. Instead, if the period over which the model is run is long enough for the inflationary effect of excess output to occur above-target output should be treated as a gain, not as a loss, and in many cases undershooting of the inflation target should also be counted as a gain. Since instances of output exceeding its target or inflation falling below its target are not uncommon, the symmetry assumption of the usual macroeconomic loss function is not just a harmless assumption that provided tractability at some small loss in accuracy. ${ }^{2}$ Instead, it can easily lead to wrong results. One possible solution is to use an asymmetric loss function (see Kunstman, 1984, Chadha and Schellekens, 19 ) Another is to replace the actual target levels by pseudo target levels set at the lowest observed value of output growth or inflation, so that all deviations from target will automatically have the same sign. This, however, may make the use of a quadratic function questionable. 


\section{ENDNOTES}

1. This assumes that policymakers are correct in their beliefs.

2. In this case the usual argument that the realism of assumptions does not matter is inapplicable, since that requires that the implications of the hypothesis can be tested.

\section{REFERENCES}

Chadha, Jagjit and Schellekens, Philip (19 ) "Monetary Policy Loss Functions: Two Cheers for the Quadratic", Board of Governors, Federal Reserve System.

Cecchetti, Stephen (2000) "Making Monetary Policy: Objectives and Rules," Oxford Review of Economic Policy 16, 43-59.

Horowitz, Ann (1987) "Loss Functions and Public Policy," Journal of Macroeconomics, 9, 489-504.

Kunstman, A. (1984) "Controlling a Linear Dynamic System According to Asymmetric Preferences." Journal of Economic Dynamics and Control, 7, 261-81

Mitchell, Douglas (1990) "The Efficient Policy Frontier under Conditions of Parameter Uncertainty and Multiple Tools," Journal of Macroeconomics, 12, 137-45.

Pearce, David (1986) o The MIT Dictionary of Modern Economics, Cambridge, MA., MIT Press,

Waud, Roger (1976) "Asymmetric Policymaker Utility Functions and Optimal Policy under Uncertainty," Econometrica, 44, 53-66. 